\title{
Should doctors talk politics with patients?
}

\author{
Cite as: CMAJ 2018 April 23;190:E520-1. doi: 10.1503/cmaj.109-5589
}

Posted on cmajnews.com on Apr. 6, 2018.

ediatricians question parents about gun safety. A group of fam-

ily doctors set timers during patient visits to demonstrate how the government is shortchanging them. Residents wear badges to protest their working conditions. It's not unusual for doctors to get political, but the rules of engagement remain unclear.

According to medical regulators, it's probably not advisable to discuss politics with patients. "The traditional view is you're supposed to be above all these things," said Dr. Ed Schollenberg, registrar of the College of Physicians and Surgeons of New Brunswick. However, "if there's no evidence that it affects care, it would be hard for us to say that it's terrible."

South of the border, some physicians are questioning that view in light of Republican efforts to dismantle the Affordable Healthcare Act. "Suddenly, being a physician and ignoring politics has become a lot like being an airplane pilot and ignoring the fact we are flying with the cabin doors wide open," Dr. Farzon Nahvi, a New Yorkbased emergency physician, wrote in the Guardian. "Patients are about to be whisked into the sky with no parachute," he argued. "Avoiding politics is not only unethical, but also unprofessional."

According to Dr. Jerry Avorn of Harvard Medical School, "if more clinicians had communicated more effectively with their patients, explaining the situation and their options as citizens and voters, some of the more threatening turns that health policy has taken might possibly have been averted."

Others contest that discussing politics may alienate patients and undermine trust in the profession. There are also reports of hospitals and universities penalizing physicians for advocacy outside of work, let alone during patient visits. Particularly for trainees, "the stakes are simply too high," said Dr. Adam Kassam, a third-year resident at Western University in Ontario.

Medical organizations differ on what they deem appropriate, if they take a stance at all. The Royal College of Physicians and Surgeons of Canada supports advocacy as a core competency of medicine. However, the college doesn't have a position on discussing politics with patients. Likewise, the Canadian Medical Association doesn't have policies or motions on the issue.

Ontario and Alberta's regulatory colleges encourage advocacy as an important component of the doctor-patient relationship. Even so, discussing politics at the

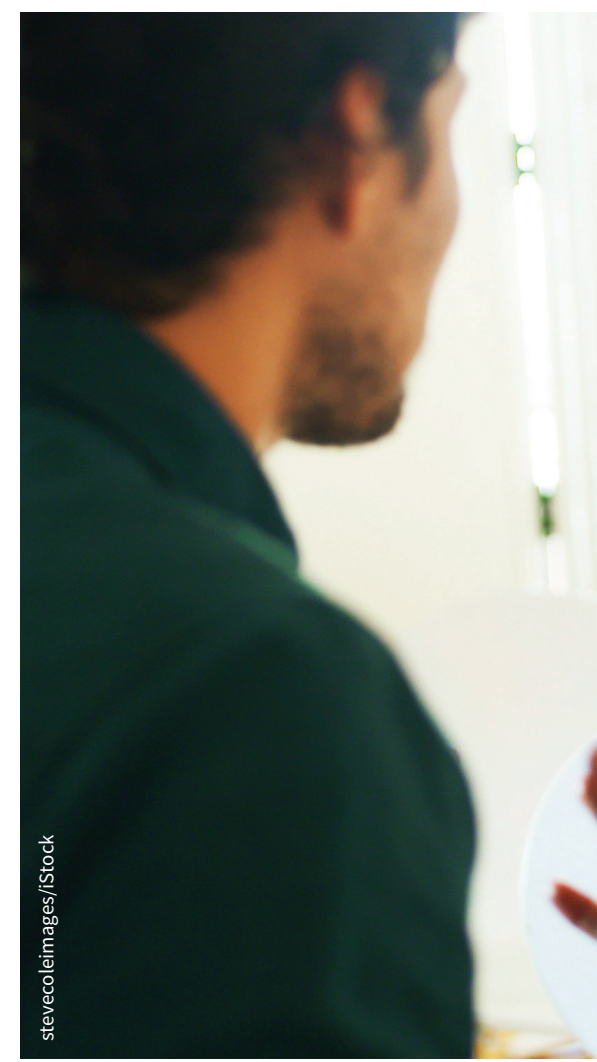

bedside may be challenging because of the inherent power imbalance between doctors and patients, said Kathryn Clarke, senior communications advisor for Ontario's college. "Acting in the best interests of the patient is paramount, as is recognizing that the physician's values may differ from those of the patient."

According to Kelly Eby, director of communications and government relations for Alberta's college, physicians should advocate "using appropriate channels, and with evidence to support their positions." The college doesn't have specific rules on discussing politics with patients, but doctors should be respectful and professional, "especially when it may

Physicians are increasingly called to be advocates, but it's not clear whether that extends to the patient visit. 
be difficult for others to separate their personal and professional opinion." She and others noted that it's unlikely that "inappropriate advocacy" would prompt a formal complaint or sanction.

Bryan Salte, associate-registrar of the College of Physicians and Surgeons of Saskatchewan, said there may be cases where a political issue is relevant to patient care. He cited recent legal battles in the US over the rights of doctors to discuss gun safety with patients. "Lots and lots of children are shot by guns lying around the house, loaded and improperly safeguarded, and it's a patient-safety issue," he said.

"I don't have trouble if it's characterized as providing information that's relevant to whatever the patient is visiting about," he added. For example, it may be appropriate to discuss the environmental benefits of going vegetarian when asked for dietary advice.

The ethics are murkier when physicians advocate for themselves on patient time. The level of intrusion matters in such cases, Salte said. For instance, the case of Ontario doctors setting timers to show patients that the province only pays for the first five minutes of each visit is "more troublesome" and intrusive than Quebec residents wearing badges to protest overwork.

Ultimately, deciding whether a conversation crosses professional boundaries is "dependent on the context, what is regarded as political, the circumstances, and what is actually said," explained Dr. Anna Ziomek, registrar for the College of Physicians and Surgeons of Manitoba.

Lauren Vogel, CMAJ 